\title{
A novel reagentless glutamate microband biosensor for real-time cell toxicity monitoring
}

\author{
G. Hughes ${ }^{1}$, R.M. Pemberton ${ }^{1}$, P.R. Fielden ${ }^{2}$, J.P. Hart ${ }^{1 *}$
}

1. Centre for Research in Biosciences, Faculty of Health and Applied Sciences, University of the West of England, Bristol, Coldharbour Lane, Bristol, BS16 1QY

2. Department of Chemistry, Lancaster University, Bailrigg, Lancaster, United Kingdom,

$$
\text { LA1 4YB }
$$

*Corresponding author: john.hart@uwe.ac.uk Tel: 01173282469 


\begin{abstract}
A reagentless glutamate biosensor was applied to the determination of glutamate released from liver hepatocellular carcinoma cells (HepG2) in response to toxic challenge from various concentrations of paracetamol. A screen printed carbon electrode (SPCE) containing the electrocatalyst Meldola's Blue (MB-SPCE) served as the electron mediator for the oxidation of NADH.
\end{abstract}

A mixture of the enzyme glutamate dehydrogenase (GLDH), cofactor nicotinamide adenine dinucleotide $\left(\mathrm{NAD}^{+}\right)$and the biopolymer chitosan (CHIT) were drop-coated onto the surface of the transducer (MB-SPCE) in a simple one step fabrication process.

The reagentless biosensor was used with amperometry in stirred solution at an applied potential of $+0.1 \mathrm{~V}$ (vs. $\mathrm{Ag} / \mathrm{AgCl}$ ). All experiments were carried out at the following conditions: $\mathrm{pH} 7$, temperature $37^{\circ} \mathrm{C}$, atmosphere $5 \% \mathrm{CO}_{2}$.

The linear range of the device was found to be $25-125 \mu \mathrm{M}$ in phosphate buffer $(75 \mathrm{mM}$, containing $0.05 \mathrm{M} \mathrm{NaCl}$ ) and $25-150 \mu \mathrm{M}$ in cell culture medium. The limits of detection (LOD) were found to be $1.2 \mu \mathrm{M}$ and $4.2 \mu \mathrm{M}$ based on three times signal to noise, using PBS

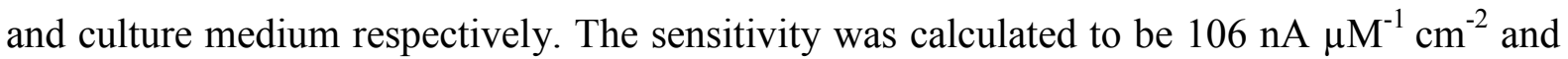
$210 \mathrm{nA} \mu \mathrm{M}^{-1} \mathrm{~cm}^{-2}$ in PBS and cell medium respectively. The response time was $\sim 60 \mathrm{~s}$ in an agitated solution.

HepG2 cells were exposed to various concentrations of paracetamol $(1 \mathrm{mM}, 5 \mathrm{mM}$ and 10 $\mathrm{mM})$ in order to investigate the drug-induced release of glutamate into the culture medium in real time. Two toxicity studies were investigated using different methods of exposure and analysis.

The first method consisted of a single measurement of the glutamate concentration, using the method of standard addition, after 24 hours incubation. The concentrations of glutamate were 
found to be $52 \mu \mathrm{M}, 93 \mu \mathrm{M}$ and $177 \mu \mathrm{M}$, released on exposure to $1 \mathrm{mM}, 5 \mathrm{mM}$ and $10 \mathrm{mM}$ paracetamol respectively.

The second method involved the continuous monitoring of glutamate released from HepG2 cells upon exposure to paracetamol over 8 hours. The concentrations of glutamate released in the presence of $1 \mathrm{mM}, 5 \mathrm{mM}$ and $10 \mathrm{mM}$ paracetamol, increased in proportion to the drug concentration, ie: $16 \mu \mathrm{M}, 28 \mu \mathrm{M}$ and $62 \mu \mathrm{M}$ respectively. This result demonstrates the feasibility of using this approach to monitor early metabolic changes after exposure to a model toxic compound.

\section{Keywords}

Glutamate, Microband, Biosensor, Cell toxicity, Amperometric, HepG2 


\section{Introduction}

Glutamate is the primary excitatory neurotransmitter in the mammalian central nervous system [1] and also has a central role in cell metabolism and function [2]. Glutamate is associated with processes such as protein synthesis/degradation, ammonia disposal, energy production and neurotransmission [3], thus glutamate plays a significant role in fundamental metabolic processes. As a result, glutamate is present in many cells such as skeletal muscle, liver, intestine and kidneys. Specifically, glutamate plays vital roles in hepatic metabolic pathways such as ureagenesis, gluconeogenesis and glutathione synthesis [4].

The concentration of intracellular glutamate is typically higher than that of extracellular glutamate. For example, within the brain, extracellular glutamate concentrations are normally within the $1-10 \mu \mathrm{M}$ range $[5,6]$ whilst intracellular glutamate concentrations are typically in the micromolar range [7]. Similar micromolar levels have been observed intracellularly in rat livers $[8,9]$.

Drug discovery is a costly and extensive process, with product development comprising up to $30-35 \%$ of the cost of bringing a new pharmaceutical compound to the market [10]. Early candidates for drug development are selected based on their pharmacological and toxicological properties which are investigated through early-stage in vitro cell-based assays [11]. Cytotoxicity assays such as neutral red, MTT (3-(4,5-dimethylthiazol-2-yl)-2,5diphenyltetrazolium bromide), LDH (lactate dehydrogenase) leakage, and protein assays are commonly used to evaluate the effects of drugs on cell metabolism and death [12]. However, these are employed by sampling off-line, or as end-point assays, and do not provide information on early toxicity events in real-time. In an approach using electrochemical biosensors to address the issue of continuous analyte monitoring in vitro, Pemberton et. al. $[13,14]$ have described the development and application of a screen-printed microband 
biosensor to follow glucose uptake by HepG2 cells in the presence of different concentrations of paracetamol.

Some reports have described the use of chitosan for the immobilization of glutamate dehydrogenase on glassy carbon [15-18], gold [19] and platinum [20] electrodes. Both reagentless and non-reagentless conventional sized glutamate biosensors have previously been developed by drop-coating the required biomolecules onto the working electrode of a screen-printed carbon electrode [21-23]. We have recently reviewed electrochemical glutamate biosensor construction and their applications in food and clinical analysis [24]. Modified Chitosan has been utilised for the covalent immobilization of glutamate oxidase [25] and lactate oxidase [26], however, as far as we are aware, there are no examples of the use of chitosan to fabricate screen-printed microband glutamate biosensors. In this paper we explore this latter possibility and demonstrate the application of the proposed device for realtime monitoring of toxicity, through the metabolic changes (glutamate release) caused by the addition of paracetamol.

\section{Materials and Methods}

\subsection{Chemicals and Reagents}

Foetal bovine serum (FBS), Minimum Essential Medium Eagle (EMEM) and all other chemicals were purchased from Sigma-Aldrich. All chemicals were of analytical grade, purchased from Sigma Aldrich, UK, except glutamate dehydrogenase (CAT: 10197734001) which was purchased from Roche, UK. The $75 \mathrm{mM}$ phosphate buffer (PB) was prepared by combining appropriate volumes of tri-sodium phosphate dodecahydrate, sodium dihydrogen

orthophosphate dihydrate and disodium hydrogen orthophosphate anhydrous solutions to yield the desired $\mathrm{pH}$. Glutamate and $\mathrm{NADH} / \mathrm{NAD}^{+}$solutions were dissolved directly in 75 $\mathrm{mM}$ PB. Chitosan was dissolved in $0.05 \mathrm{M} \mathrm{HCl}(\mathrm{pH}<3.0)$ to produce a $0.05 \%$ solution 
following up to 10 minutes sonication. A $25 \mathrm{mM}$ stock solution of glutamate (monosodium glutamate) was utilised for glutamate calibrations. A $500 \mathrm{mM}$ stock of paracetamol in $100 \%$ ethanol was diluted with cell culture media and filtered sterilised $(0.2 \mu \mathrm{m})$ before use.

\subsection{Apparatus}

All electrochemical experiments were conducted with a two electrode system consisting of a carbon working electrode containing MB (MB-SPCE, Gwent Electronic Materials Ltd; Ink Code: $\mathrm{C} 2030519 \mathrm{P} 5)$, and a $\mathrm{Ag} / \mathrm{AgCl}$ reference electrode (The difference between the screenprinted $\mathrm{Ag} / \mathrm{AgCl}$ electrode and the conventional $\mathrm{Ag} / \mathrm{AgCl}(3 \mathrm{M} \mathrm{NaCl})$ was $+80 \mathrm{mV})(\mathrm{GEM}$ Product Code C61003P7); both printed onto PVC (poly vinyl chloride). The electrodes were connected to the potentiostat using gold clips. Microband electrodes/biosensors and reference electrodes were held by gold clips attached to cork lids which were push-fitted into 6-well plate wells (Corning®). Electrodes were connected to a PG580RM 5-channel potential (Uniscan Instruments Ltd, Buxton, UK; www.uniscan.com) which was controlled using UiEChem software (Version 2.02), for both single and multiple parallel well experiments. All cell culture work and dosing with paracetamol was conducted under a sterile conditions. The cork lid electrode holders was sterilised with $70 \%$ ethanol spray. The electrodes themselves were not sterilised as the ethanol would potentially damage the enzyme and cofactor. Experiments utilising culture medium and HepG2 cells were carried out in an incubator with a $5 \% \mathrm{CO}_{2}$ atmosphere at $37^{\circ} \mathrm{C}$ in order to maintain the correct $\mathrm{pH}$. Sonications were performed with a Devon FS100 sonicator (Ultrasonics, Hove, Sussex, UK).

\subsection{Principle of operation of the biosensor}

The overall principle of operation of the biosensor is shown in Figure 1. Glutamate in solution is oxidised to form 2-oxoglutarate in the presence of the immobilised enzyme glutamate dehydrogenase (GLDH) and $\mathrm{NAD}^{+}$; the products $\mathrm{NADH}$ and $\mathrm{NH}_{4}^{+}$are formed 
during this reaction. NADH chemically reduces Meldola's Blue which subsequently undergoes electrochemical oxidation at the electrode surface to produce the analytical response.

\subsection{Biosensor Fabrication}

The fabrication procedure is illustrated in Figure 2. Five microliters of CHIT $(0.05 \%$ in $0.05 \mathrm{M} \mathrm{HCl}$ ) were drop-coated onto the surface of a $3 \mathrm{~mm}^{2}$ working electrode (a), followed by $9 \mu \mathrm{L}$ of $\mathrm{GLDH}(3 \mathrm{U} / \mu \mathrm{L})$ and $1 \mu \mathrm{L}$ of $\mathrm{NAD}^{+}(106 \mu \mathrm{g})(\mathrm{b})$. The biosensor was then left to dry overnight at $4^{\circ} \mathrm{C}(\mathrm{c})$. Once dried, insulating tape was used to cover the working area and some of the electrode track (d). Microbiosensors were formed by cutting through the working electrode using scissors to expose a 3mm-long working electrode edge (e).

\subsection{Electron Microscopy}

The microband biosensor was attached to a $9 \mathrm{~mm}$-diameter double sided adhesive carbon disc on a $45^{\circ}$ angled aluminium stub. A cross section of the edge of the electrode was examined using a Philips XL30 environmental scanning electron microscope (ESEM).

\subsection{HepG2 cell culture}

The HepG2 (Human Caucasian Hepatocyte Carcinoma) cell line (obtained from European Collection of Authenticated Cell Cultures, ECACC) was cultured as a monolayer in $75 \mathrm{~cm}^{2}$ flasks, in a $5 \% \mathrm{CO}_{2}$-in-air atmosphere at $37{ }^{\circ} \mathrm{C}$, at an initial density of $2 \times 10^{5}$ cells $\mathrm{cm}^{-2}$. Cells were counted using a haemocytometer. The culture medium was EMEM containing 10\% FBS, 1\% non-essential amino acids (NEAA), $200 \mathrm{nM}$ L-glutamine. When confluent, the cells were detached by trypsinisation, and resuspended in culture medium. For the assays described, cells were plated at a density of $2 \times 10^{6}$ cells $\mathrm{mL}^{-1}$ in $6 \mathrm{~mL}$ volumes into 6 -well tissue culture plates. 


\subsection{Voltammetry and amperometry}

All cyclic voltammetric studies were carried out by lowering a microband biosensor, in combination with a screen-printed $\mathrm{Ag} / \mathrm{AgCl}$ reference electrode, into the voltammetric cell containing a $10 \mathrm{ml}$ solution of $75 \mathrm{mM}$ phosphate containing $50 \mathrm{mM} \mathrm{NaCl}$ (PBS). For studies with $\mathrm{NADH}$, the following procedure was employed: phosphate buffer solution was carried out in the presence and absence of oxygen, followed by $15 \mathrm{~s}$ equilibration at open circuit voltage. The working electrode potential scanned from an initial potential of $-0.5 \mathrm{~V}$ to the switching potential, $+0.6 \mathrm{~V}$, at a scan rate of $5 \mathrm{mVs}^{-1}$.

All of the studies involved the use of six-well plates containing appropriate control or test solutions which were agitated using a gyrorotator at a fixed speed which ensured thorough mixing of the cells with paracetamol. Gyrorotation of the plates was maintained for the duration of the experiments. All amperometric measurements were carried using an applied potential of $+0.1 \mathrm{~V}$. A calibration study was performed using culture media. Additions of glutamate were made so that the final concentrations in the solution were in the range of 25 $150 \mu \mathrm{M}$. All studies were carried out at $\mathrm{pH} 7.4$.

\subsection{Real-time monitoring of glutamate in cell culture medium in the presence/absence of cells and toxic compounds.}

HepG2 cells grown in T75 flasks, once $80 \%$ confluent were trypsinized and transferred to six well tissue culture plates, along with $6 \mathrm{mls}$ of cell medium under sterile conditions. 24 hours were allowed to pass to allow the cells to fully adhere to the bottom of the wells. Appropriate aliquots of paracetamol (from $100 \mathrm{mM}$ in $20 \%$ ethanol, diluted with cell culture medium) were then exchanged for medium in order to achieve the desired final concentrations in a $6 \mathrm{ml}$ 
volume. The cork lids which held the microband glutamate biosensor and reference electrode were push-fitted into each well. A small (1 mm diameter) hole in the top surface of each sensor cork lid allowed air to escape, avoided pressure build-up during the push-fitting step and allowed for gaseous exchange to maintain the $\mathrm{pH}$ of the media.

The electrode leads were extended from the inside of the incubator through the temperature seal and connected to respective channels of the multichannel potentiostat. The 6 -well plate was rotated utilising a gyro-rotator within an incubator at $37{ }^{\circ} \mathrm{C}, 5 \% \mathrm{CO}_{2}$ in the air atmosphere. An operating potential of $+0.1 \mathrm{~V}$ vs $\mathrm{Ag} / \mathrm{AgCl}$ was applied to each working electrode, and the instrument was run in amperometric mode for 8 hours for the real-time experiments. The resulting data were exported into Microsoft Excel and plotted as currentversus-time graphs.

\section{Results and Discussion}

\subsection{Microband Biosensor}

An SEM image of the edge of a microband biosensor is shown in Fig 3. The image is labelled to indicate the layers of the individual components. The thickness of the original Meldola's Blue screen printed working electrode was $20 \mu \mathrm{m}$. The area of the exposed edge of the microband electrode was $60,000 \mu \mathrm{m}^{2}(3 \mathrm{~mm} \times 20 \mu \mathrm{m})$.

\subsection{Cyclic voltammetric behaviour of NADH using a microband biosensor.}

Cyclic voltammograms were obtained with the microband biosensors in a solution containing NADH, $75 \mathrm{mM}$ PBS pH 7; a scan rate of $5 \mathrm{mVs}^{-1}$ was used. Typical cyclic voltammetric responses for NADH are shown in Fig 4. The spikes present on the voltammogram arise from the silver redox reaction due to the silver contained within the ink. In the presence of NADH the responses show sigmoidal and steady state behaviour; these show that an increase in the 
anodic peak potential occurred with increasing concentrations of NADH. This behaviour is indicative of the electro-catalytic oxidation of NADH [27] and is a pre-requisite for applications in monitoring glutamate.

The steady state currents resulting from this electrocatalytic behaviour are obtained for both deoxygenated (Figure 4) and oxygenated (Supp Figure 1) solutions of NADH and are very similar. It may also be noted, at a voltage of $+0.5 \mathrm{~V}$, there is an observed rise in the anodic current, this arises owing to the potential being sufficiently positive to cause the direct oxidation of NADH at the carbon particles of the modified screen printed electrode. We have observed this second oxidation in previous work for NADH at MB-SPCE [27]. It appears that although small cathodic peaks appear in Figure 4, they are considerably smaller in the absence of oxygen compared to those in the presence of oxygen. This is clearer by referring to the blank red $\mathrm{CV}$ (oxygen present) compared to the blue $\mathrm{CV}$ (oxygen absent). This we believe can be explained by the presence of a small concentration of residual oxygen in the solution, following the deoxygenation procedure. An applied potential of $+0.1 \mathrm{~V}$ was chosen for the operation of the biosensor, in order to avoid oxidising interferences that may be present within complex cell media.

\subsection{Calibration studies of glutamate in cell culture medium using a microband biosensor and operational stability.}

Fig 5A shows an amperogram obtained with different glutamate concentrations using the microband biosensors in agitated culture medium at an applied potential of $+0.1 \mathrm{~V}$ (versus $\mathrm{Ag} / \mathrm{AgCl})$. Each arrow indicates the addition of an aliquot of $6 \mu \mathrm{L}$ of a $25 \mathrm{mM}$ glutamate stock solution into $6 \mathrm{mLs}$ of culture medium. The corresponding calibration plot is shown in Fig 5B. The standard deviations represented are based on $\mathrm{n}=5$ runs using separate biosensors. The biosensor, functioning in cell media, possessed the following characteristics: 
linear range, $25-150 \mu \mathrm{M}$; sensitivity, $0.13 \mathrm{nA} / \mu \mathrm{M}$; and a theoretical limit of detection of 4.24 $\mu \mathrm{M}$ (based on three times signal to noise). At this point the biosensor assay appears to be suitable for our proposed real time cell toxicity studies.

The operational stability of the biosensor was investigated over a period of 8 hours. The microband biosensor was inserted into an agitated cell media solution containing $100 \mu \mathrm{M}$ of glutamate and after steady state had been reached an aliquot of paracetamol (10mM) was added to the solution. Supplementary Figure 2 demonstrates that the addition of paracetamol does not influence the magnitude of the glutamate response over a period of 8 hours. This observation is important for the studies described in the following sections (3.4/3.5).

\subsection{Glutamate determination in cell culture medium after 24 hours' exposure of HepG2 cells to various concentrations of paracetamol.}

Fully confluent HepG2 cells were exposed to various concentrations of paracetamol ( $1 \mathrm{mM}, 5$ $\mathrm{mM}$ and $10 \mathrm{mM}$ ) for 24 hours. After exposure, the cell medium was collected and the cells were disposed of. The microband biosensor was initially immersed in untreated cell medium, and once a steady-state baseline was achieved the biosensor was transferred to the postexposure cell media. This resulted in an increase in current as a result of the additional glutamate released by the HepG2 cells. Once steady-state had been reached, standard additions of $25 \mathrm{mM}$ glutamate were added to the cell. The response generated by the endogenous glutamate present in the cell medium and the additions of glutamate were plotted against concentration. From this standard addition plot, the original concentration of glutamate found in the cell media was determined.

The average endogenous concentrations for glutamate released from the HepG2 cells were 52 $\mu \mathrm{M}(\mathrm{CoV}: 13.74 \%, \mathrm{n}=3), 93 \mu \mathrm{M}(\mathrm{CoV}: 18.41 \%, \mathrm{n}=3)$ and $177 \mu \mathrm{M}(\mathrm{CoV}: 14.54 \% \mathrm{n}=3)$ for $1 \mathrm{mM}, 5 \mathrm{mM}, 10 \mathrm{mM}$ doses of paracetamol respectively. A bar chart (Fig 6) illustrates the 
relationship between increasing paracetamol concentration, and increased release of glutamate. The data shown for each concentration of paracetamol is based on the determination of the glutamate concentration released into the culture medium of three separately treated flasks of HepG2. The standard deviations shown are based on $n=3$.

\subsection{Real-time monitoring of glutamate release from HepG2 cells exposed to various concentrations of paracetamol.}

Fully confluent HepG2 cells in six well plates were incubated with various concentrations of paracetamol $(1 \mathrm{mM}, 5 \mathrm{mM}$ and $10 \mathrm{mM})$ as described above. Microband biosensors were placed into the wells within 5 minutes of paracetamol addition; the release of glutamate was then monitored in real time over an 8 hour period at the applied potential of $+0.1 \mathrm{~V}$. Figure 7 illustrates an example of the currents generated as a result of glutamate released from the HepG2 cells and monitored by the glutamate biosensors for each concentration of paracetamol. As with the previous method, each repeat is based on a separate analysis of HepG2 cells.

The concentrations of glutamate in the wells at the end of the 8 hour experiment were determined from a calibration plot. The relationship between the glutamate concentration released after 8 hours, and the concentrations of paracetamol is shown in Figure 8 . The following values have been obtained; $15 \mu \mathrm{M}(1 \mathrm{mM}, \mathrm{CoV}: 2.4 \%, \mathrm{n}=3), 28 \mu \mathrm{M}(5 \mathrm{mM}, \mathrm{CoV}$ : $1.96 \%, \mathrm{n}=3)$ and $62 \mu \mathrm{M}(10 \mathrm{mM}, \mathrm{CoV}: 5.79 \%, \mathrm{n}=3)$, indicating high reproducibility.

Clearly, the increase in the current due to the release of glutamate correlates with the increasing paracetamol concentration. The mechanism behind the release of glutamate is likely to be due to the Phase I and Phase II metabolism of paracetamol by the enzyme CYP450 present within HepG2 cells. CYP450 typically converts paracetamol to the toxic byproduct N-acetyl-p-benzoquinone imine (NAPQI). At sub-lethal concentrations of 
paracetamol, glutathione conjugates the NAPQI to a non-harmful product. However, at higher doses of paracetamol the glutathione is unable to regenerate sufficiently to process the NAPQI [28]. NAPQI subsequently binds to membrane proteins [29][30], resulting in hepatic necrosis, which leads to the rupture of the cell membrane and release of its contents. With increasing concentrations of paracetamol, the number of liver cells undergoing hepatic necrosis will increase, resulting in the release of glutamate from the cells. The extent to which the glutamate is released scales accordingly with the increasing concentrations of paracetamol metabolised by the cells.

The advantage of monitoring the cells in real time is that it is possible to determine the length of time taken for the paracetamol to have an effect upon the metabolism of the HepG2 cells. As shown in Fig. 7, it appears to take 1 hour (3600s) for glutamate to begin to be released from the cells and this timing seems to be independent of the drug concentration. The average timing for the glutamate release is as follows $(\mathrm{n}=3) ; 1 \mathrm{mM}-2916 \mathrm{~s}, 5 \mathrm{mM}-2666 \mathrm{~s}$ and $10 \mathrm{mM}-3566 \mathrm{~s}$. After 7 hours the currents begin to reach steady state, suggesting that the release of glutamate from the cells has ceased.

\section{Conclusions}

This paper has described the successful development and application of an amperometric, reagentless, glutamate microband biosensor. We believe that this is achieved by a combination of mainly crosslinking and partial entrapment of the biocomponents onto the surface of the working electrode using the biopolymer, chitosan. The former occurs through interaction of the amine groups of chitosan with the carboxyl groups of glutamate dehydrogenase; a similar suggestion has been made by Baker et.al [31]. The entrapment process is likely to involve partial diffusion of the enzyme/cofactor layer into the chitosan layer, which subsequently forms a hydro-gel. It should be mentioned that in the absence of 
chitosan on the surface of the biosensor, non-steady-state currents were obtained in response to additions of glutamate (Supp Fig 3.). This may be attributed to the poor immobilization of the enzyme/cofactor on the surface of the screen-printed electrode and highlights the importance of the chitosan layer.

The device has been successfully applied to the determination of glutamate released by HepG2 cells in response to toxic challenge by paracetamol. The device was used to determine the concentration of glutamate released by cells into the culture media after 24 hours by standard addition. The microband biosensor was also applied to the real-time monitoring of glutamate released by cells over 8 hours. In repeat experiments, the toxicity induced release of glutamate from the HepG2 cells resulted in currents which corresponded with the concentrations of paracetamol utilised. We observed a high level of repeatability with each study, as highlighted by the low coefficients of variation achieved. The experimental setup $\left(37^{\circ} \mathrm{C}\right.$ in an incubator with a $5 \% \mathrm{CO}_{2}$ atmosphere) reduced the likelihood of inaccuracy by maintaining a steady temperature, $\mathrm{pH}$ and a favourable environment for the cell media/cells.

The monitoring of real time metabolic events by using an electrochemical microband biosensor holds great potential for further development. The simple drop-coating fabrication procedure involving the entrapment of the biocomponents by chitosan, and the simple cutting technique to fabricate the micro biosensor, could be a potential platform for developing other microband biosensors based on dehydrogenase enzymes.

\section{Acknowledgements}

The authors wish to thank the University of the West of England, Bristol for funding. Gwent Electronic Materials are thanked for the provision of the MB-SPCEs. Thanks to Dr. D. Patton for his help in obtaining the SEM images. 


\section{References}

[1] B.S. Meldrum, Glutamate as a neurotransmitter in the brain: review of physiology and pathology., J. Nutr. 130 (2000) 1007S-15S.

http://www.ncbi.nlm.nih.gov/pubmed/10736372 (accessed March 16, 2015).

[2] P. Newsholme, J. Procopio, M.M.R. Lima, T.C. Pithon-Curi, R. Curi, Glutamine and glutamate--their central role in cell metabolism and function., Cell Biochem. Funct. 21 (2003) 1-9. doi:10.1002/cbf.1003.

[3] A. Kelly, C. Stanley, Disorders of glutamate metabolism, Ment. Retard. Dev. ... 295 (2001) 287-295. http://onlinelibrary.wiley.com/doi/10.1002/mrdd.1040/full (accessed September 30, 2013).

[4] K. Sejrsen, T. Hvelplund, M.O. Nielsen, Ruminant Physiology: Digestion, Metabolism and Impact of Nutrition on Gene Expression, Immunology and Stress, Wageningen Academic Pub, 2006.

https://books.google.com/books?id=L6PGYCco2R0C\&pgis=1 (accessed July 9, 2015).

[5] N.C. Danbolt, Glutamate uptake., Prog. Neurobiol. 65 (2001) 1-105.

http://www.ncbi.nlm.nih.gov/pubmed/11369436 (accessed September 30, 2013).

[6] C.F. Zorumski, S. Mennerick, J. Que, Modulation of excitatory synaptic transmission by low concentrations of glutamate in cultured rat hippocampal neurons., J. Physiol. 494 (1996) 465-477. doi:10.1113/jphysiol.1996.sp021506.

[7] R. Dingledine, P.J. Conn, Peripheral glutamate receptors: molecular biology and role in taste sensation., J. Nutr. 130 (2000) 1039S-42S.

http://www.ncbi.nlm.nih.gov/pubmed/10736377 (accessed March 10, 2015).

[8] W.J.C. Geerts, A. Jonker, L. Boon, A.J. Meijer, R. Charles, C.J.F. Van Noorden, et al., In Situ Measurement of Glutamate Concentrations in the Periportal, Intermediate, and Pericentral Zones of Rat Liver, J. Histochem. Cytochem. 45 (1997) 1217-1229. doi:10.1177/002215549704500905.

[9] R. Hems, M. Stubbs, H.A. Krebs, Restricted permeability of rat liver for glutamate and succinate., Biochem. J. 107 (1968) 807-15.

http://www.pubmedcentral.nih.gov/articlerender.fcgi?artid=1198752\&tool=pmcentrez \&rendertype $=$ abstract $($ accessed March 18, 2015).

[10] P. Suresh, P.K. Basu, Improving Pharmaceutical Product Development and Manufacturing: Impact on Cost of Drug Development and Cost of Goods Sold of Pharmaceuticals, J. Pharm. Innov. 3 (2008) 175-187. doi:10.1007/s12247-008-9043-1.

[11] A. Astashkina, B. Mann, D.W. Grainger, A critical evaluation of in vitro cell culture models for high-throughput drug screening and toxicity., Pharmacol. Ther. 134 (2012) 82-106. doi:10.1016/j.pharmthera.2012.01.001.

[12] G. Fotakis, J.A. Timbrell, In vitro cytotoxicity assays: comparison of LDH, neutral red, MTT and protein assay in hepatoma cell lines following exposure to cadmium chloride., Toxicol. Lett. 160 (2006) 171-7. doi:10.1016/j.toxlet.2005.07.001.

[13] R. Pemberton, T. Cox, R. Tuffin, I. Sage, G. Drago, N. Biddle, et al., Microfabricated glucose biosensor for culture well operation, Biosens. Bioelectron. (2013). 
http://eprints.uwe.ac.uk/18577/ (accessed March 26, 2015).

[14] R.M. Pemberton, J. Xu, R. Pittson, G.A. Drago, J. Griffiths, S.K. Jackson, et al., A screen-printed microband glucose biosensor system for real-time monitoring of toxicity in cell culture., Biosens. Bioelectron. 26 (2011) 2448-53. doi:10.1016/j.bios.2010.10.030.

[15] S. Chakraborty, C. Retna Raj, Amperometric biosensing of glutamate using carbon nanotube based electrode, Electrochem. Commun. 9 (2007) 1323-1330. doi:10.1016/j.elecom.2007.01.039.

[16] X. Tan, M. Li, P. Cai, L. Luo, X. Zou, An amperometric cholesterol biosensor based on multiwalled carbon nanotubes and organically modified sol-gel/chitosan hybrid composite film., Anal. Biochem. 337 (2005) 111-20. doi:10.1016/j.ab.2004.10.040.

[17] M. Zhang, A. Smith, W. Gorski, Carbon nanotube-chitosan system for electrochemical sensing based on dehydrogenase enzymes., Anal. Chem. 76 (2004) 5045-50. doi:10.1021/ac049519u.

[18] S. Chakraborty, C.R. Raj, Mediated electrocatalytic oxidation of bioanalytes and biosensing of glutamate using functionalized multiwall carbon nanotubes-biopolymer nanocomposite, J. Electroanal. Chem. 609 (2007) 155-162. doi:10.1016/j.jelechem.2007.06.024.

[19] B. Batra, C.S. Pundir, An amperometric glutamate biosensor based on immobilization of glutamate oxidase onto carboxylated multiwalled carbon nanotubes/gold nanoparticles/chitosan composite film modified Au electrode., Biosens. Bioelectron. 47 (2013) 496-501. doi:10.1016/j.bios.2013.03.063.

[20] M. Zhang, C. Mullens, W. Gorski, Amperometric glutamate biosensor based on chitosan enzyme film, Electrochim. Acta. 51 (2006) 4528-4532.

doi:10.1016/j.electacta.2006.01.010.

[21] G. Hughes, R.M. Pemberton, P.R. Fielden, J.P. Hart, Development of a Disposable Screen Printed Amperometric Biosensor Based on Glutamate Dehydrogenase, for the Determination of Glutamate in Clinical and Food Applications, Anal. Bioanal. Electrochem. 6 (2014) 435-449. http://abechem.com/No. 4-2014/2014,6_4_,435449.pdf.

[22] G. Hughes, R.M. Pemberton, P.R. Fielden, J.P. Hart, Development of a novel reagentless, screen-printed amperometric biosensor based on glutamate dehydrogenase and NAD + , integrated with multi-walled carbon nanotubes for the determination of glutamate in food and clinical applications, Sensors Actuators B Chem. (2015). doi:10.1016/j.snb.2015.04.066.

[23] R. Khan, W. Gorski, C.D. Garcia, Nanomolar Detection of Glutamate at a Biosensor Based on Screen-Printed Electrodes Modified with Carbon Nanotubes, Electroanalysis. 23 (2011) 2357-2363. doi:10.1002/elan.201100348.

[24] G. Hughes, R.M. Pemberton, P.R. Fielden, J.P. Hart, The design, development and application of electrochemical glutamate biosensors, Trends Anal. Chem. In press. (2015).

[25] M. Zhang, C. Mullens, W. Gorski, Chitosan-Glutamate Oxidase Gels: Synthesis, Characterization, and Glutamate Determination, Electroanalysis. 17 (2005) 21142120. doi:10.1002/elan.200503348. 
[26] X. Wei, M. Zhang, W. Gorski, Coupling the lactate oxidase to electrodes by ionotropic gelation of biopolymer., Anal. Chem. 75 (2003) 2060-4. doi:10.1021/ac020765k.

[27] S.D. Sprules, J.P. Hart, R. Pittson, S. a Wring, Evaluation of a new disposable screenprinted sensor strip for the measurement of NADH and its modification to produce a lactate biosensor employing microliter volumes, Electroanalysis. 8 (1996) 539-543. http://doi.wiley.com/10.1002/elan.1140080608.

[28] J.R. Mitchell, D.J. Jollow, W.Z. Potter, J.R. Gillette, B.B. Brodie, Acetaminopheninduced hepatic necrosis. IV. Protective role of glutathione., J. Pharmacol. Exp. Ther. 187 (1973) 211-7. http://www.ncbi.nlm.nih.gov/pubmed/4746329 (accessed March 30, 2015).

[29] M. Moore, H. Thor, G. Moore, S. Nelson, P. Moldéus, S. Orrenius, The toxicity of acetaminophen and N-acetyl-p-benzoquinone imine in isolated hepatocytes is associated with thiol depletion and increased cytosolic Ca2+., J. Biol. Chem. 260 (1985) 13035-40. http://www.ncbi.nlm.nih.gov/pubmed/2932433 (accessed June 3, 2015).

[30] Y. Dai, A.I. Cederbaum, Cytotoxicity of acetaminophen in human cytochrome P4502E1-transfected HepG2 cells., J. Pharmacol. Exp. Ther. 273 (1995) 1497-505. http://www.ncbi.nlm.nih.gov/pubmed/7791125 (accessed June 3, 2015).

[31] S. Baker, W. P. Wiesmann, R. Shannon, Chitosan-derivative compounds and methods of controlling microbial populations, (2009).

http://www.google.com/patents/EP2035338A2?cl=en (accessed April 4, 2016). 


\section{Figure Captions}

Figure 1: Schematic displaying interaction between the enzyme glutamate dehydrogenase, cofactor $\mathrm{NAD}^{+}$and the analyte glutamate at the surface of the electrode, resulting in the subsequent generation of the analytical response.

Figure 2: Scheme showing the various steps involved in the fabrication of the reagentless glutamate biosensor. a) Drop coating of CHIT b) drop coating of GLDH and NAD ${ }^{+}$c) drying d) application of insulating tape across working area of electrode e) cutting through working electrode to expose the micro biosensor.

Figure 3. SEM image of the cross section of the microband biosensor electrode. The layers are described as follows; 1) PVC Substrate 2) MB-SPCE 3) CHIT 4) GLDH/NAD ${ }^{+}$5) Insulating Tape

Figure 4: Cyclic voltammograms of a reagentless glutamate biosensor in the presence and absence of 2.5 and $5 \mathrm{mM}$ NADH (PBS, pH 7.4, oxygenated and deoxygenated solution)

Figure 5: A) Amperogram carried out with the reagentless glutamate micro biosensor in cell media. Each arrows indicate an aliquot of $6 \mu \mathrm{L}$ of a $25 \mathrm{mM}$ glutamate stock solution into $6 \mathrm{mLs}$ of cell media. B) Resulting calibration plot. Each point represents the mean current response for $\mathrm{n}=3$ runs $+/-1 \mathrm{SD}$.

Figure 6: Bar chart illustrating the concentrations of glutamate present in cell media following 24 hours' incubation in the presence of various concentrations of paracetamol. Each plot represents the mean current response for $\mathrm{n}=3$ runs $+/-1 \mathrm{SD}$.

Figure 7: Amperograms generated by reagentless glutamate microband biosensors monitoring the glutamate released by HepG2 cells incubated with various concentrations of paracetamol ( $1 \mathrm{mM}, 5 \mathrm{mM}, 10 \mathrm{mM}) .3600 \mathrm{~s}=1$ hour.

Figure 8: Bar chart illustrating the currents generated as a result of glutamate generated after 8 hours of incubation in the presence of various concentrations of paracetamol in real time, $n$ $=3,+/-1 \mathrm{SD}$ 


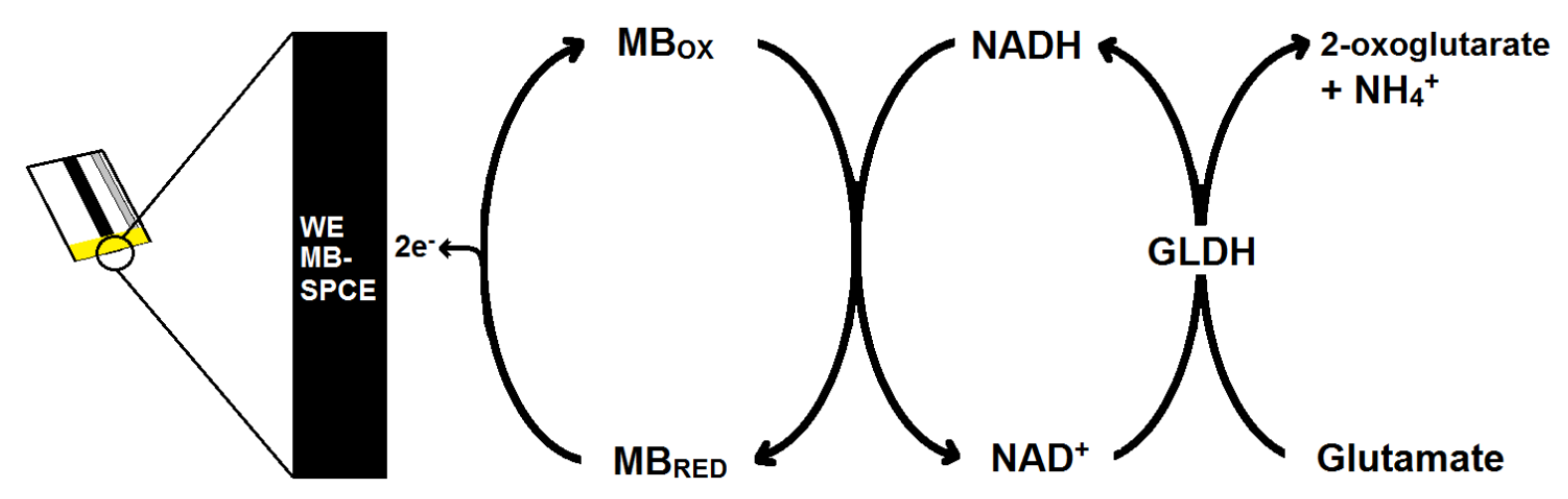

Figure 1

a)

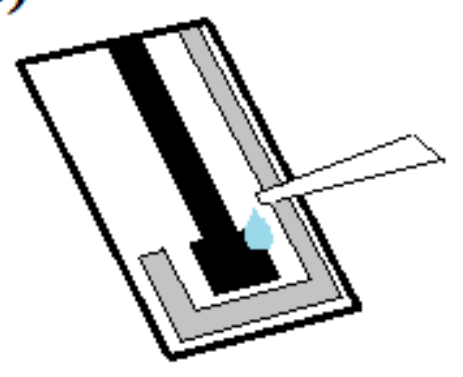

b)

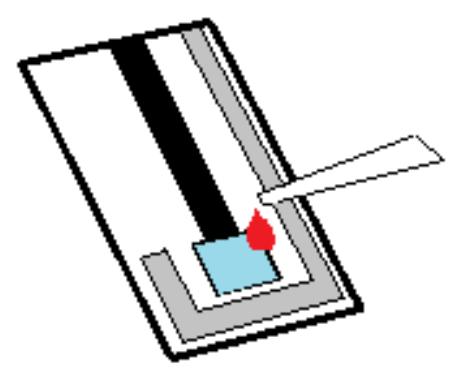

c)

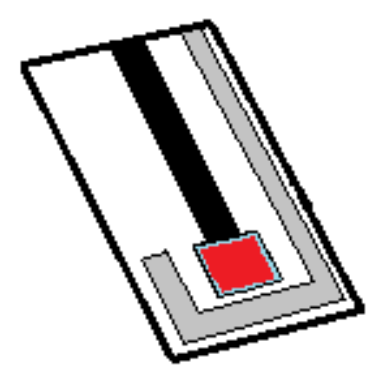

d)

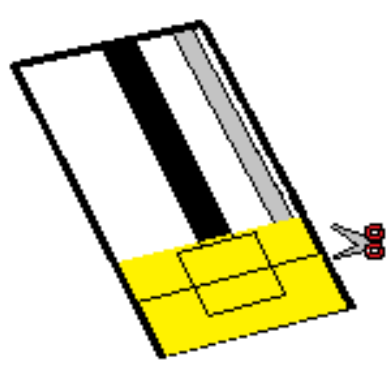

e)

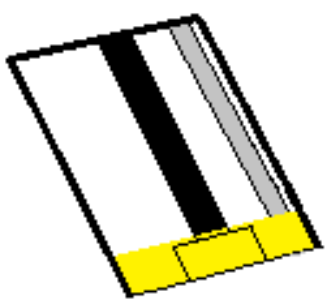

Figure 2 


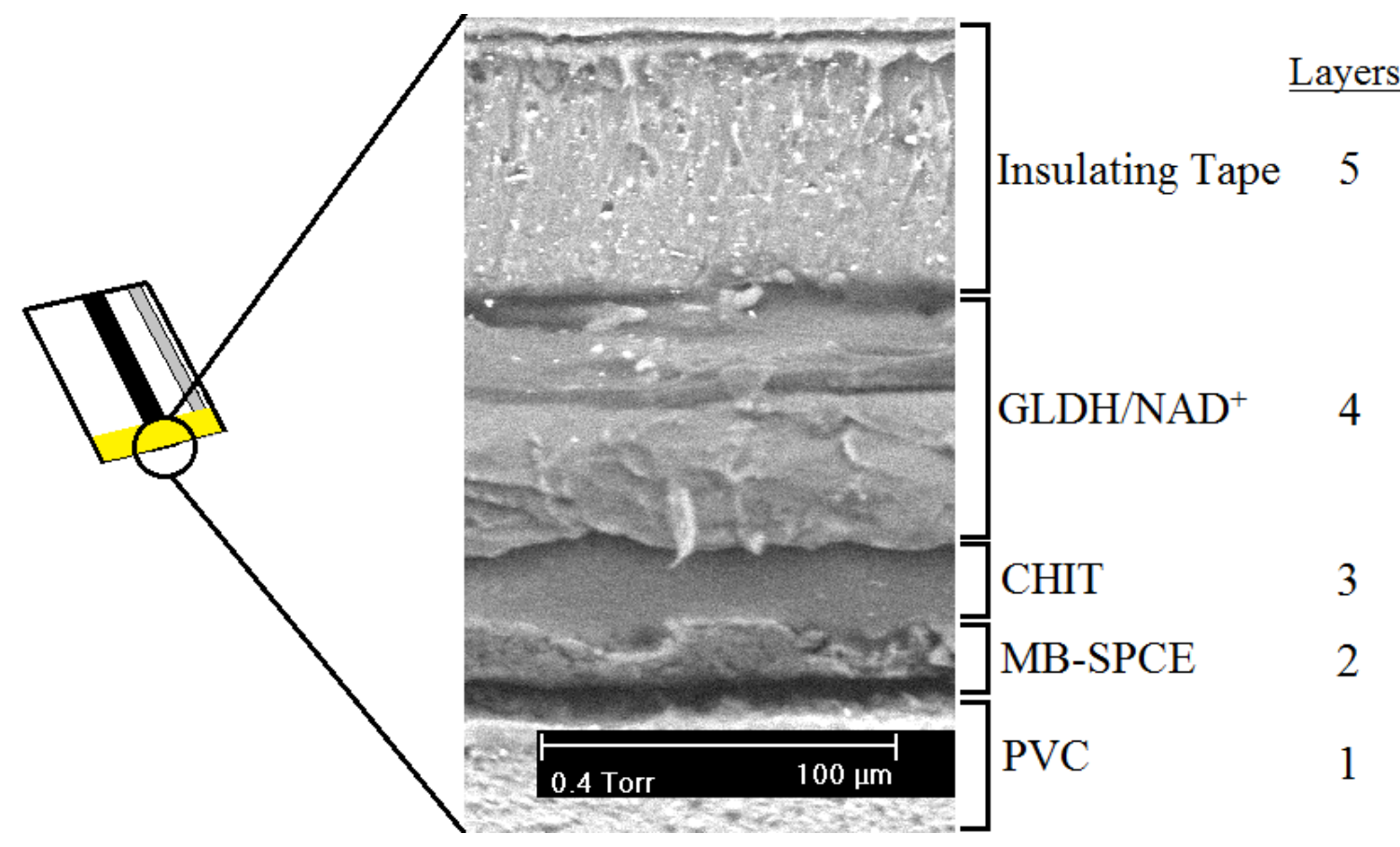

Figure 3

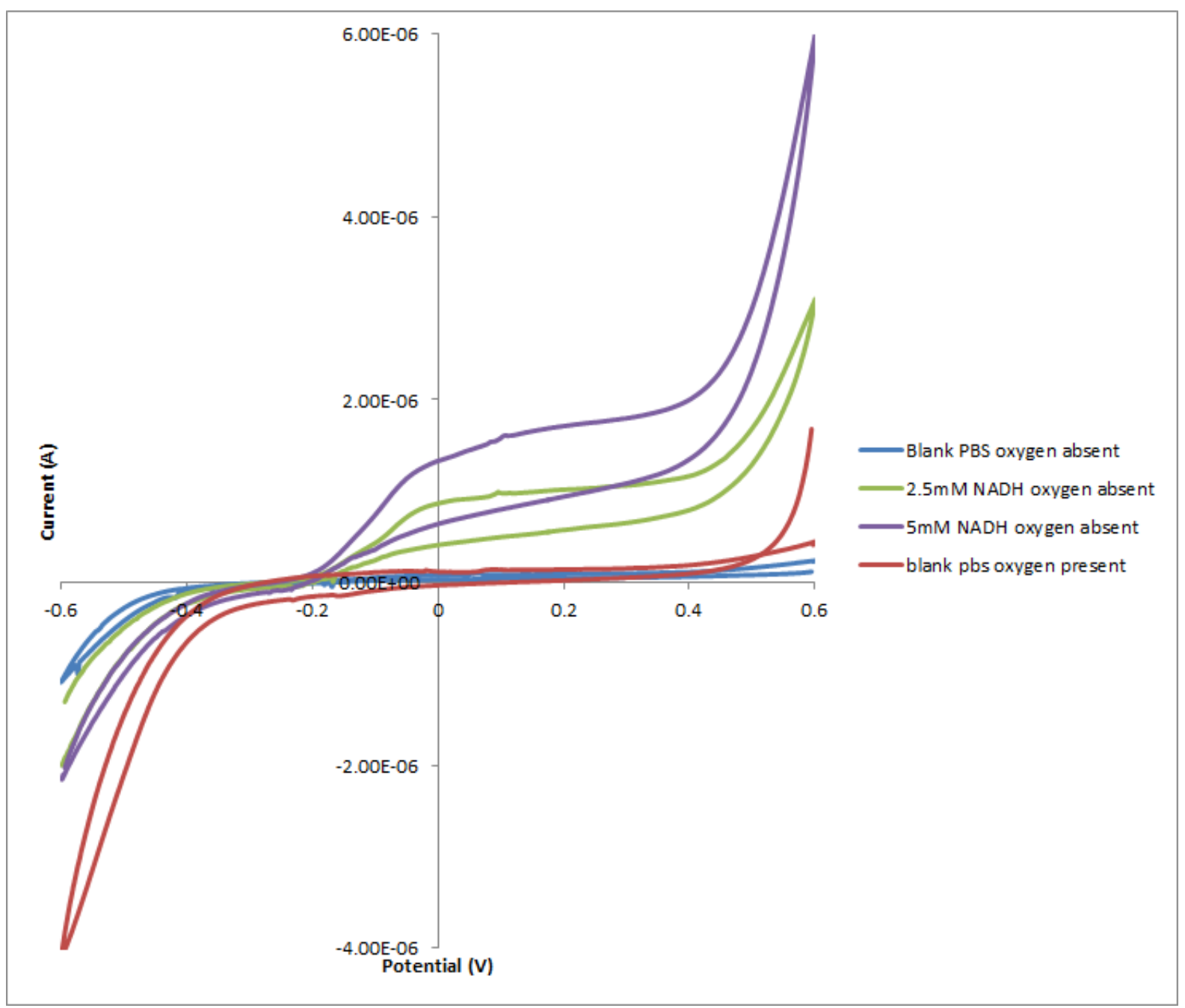

Figure 4 


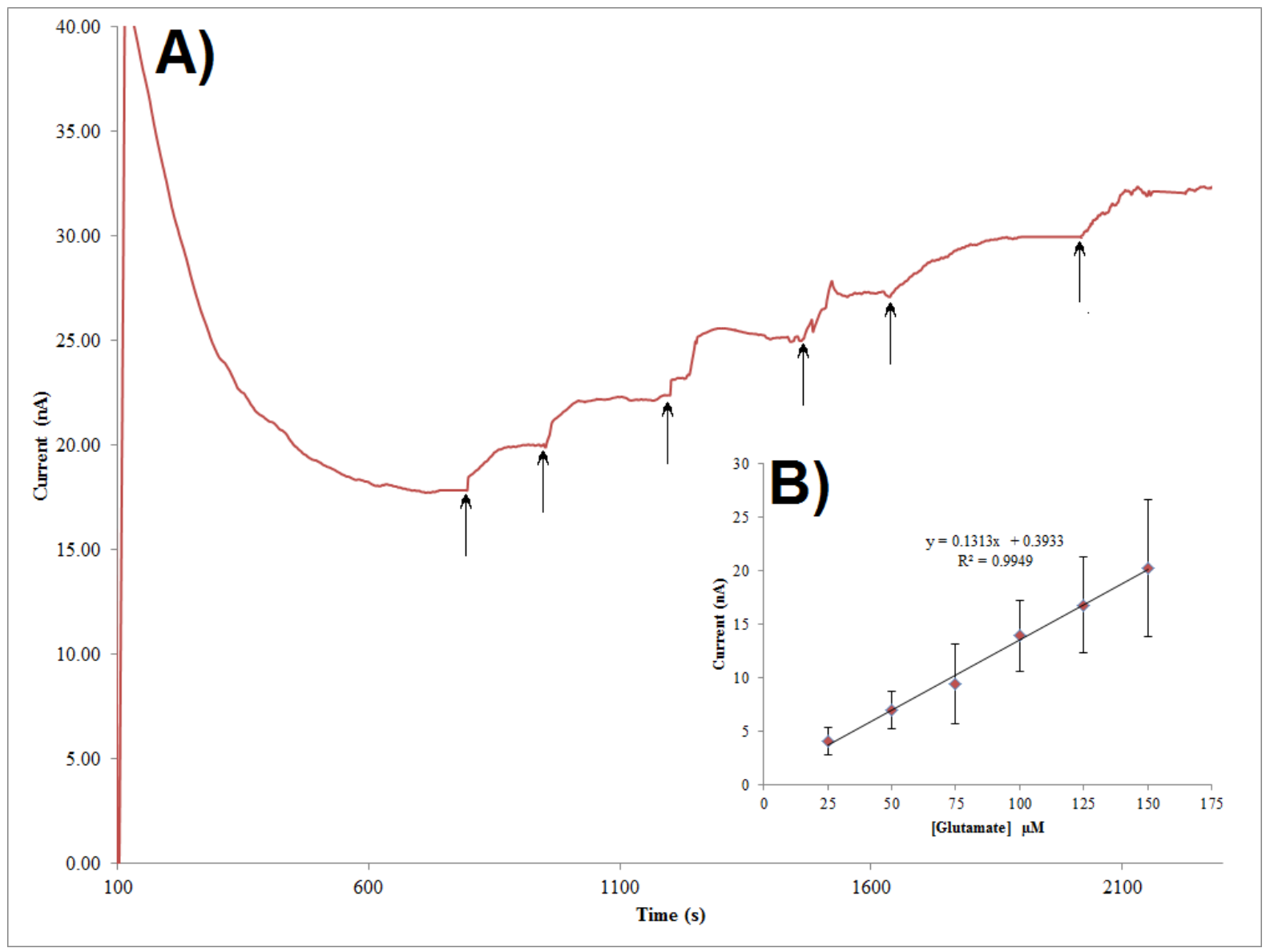

Figure $5 \mathrm{AB}$

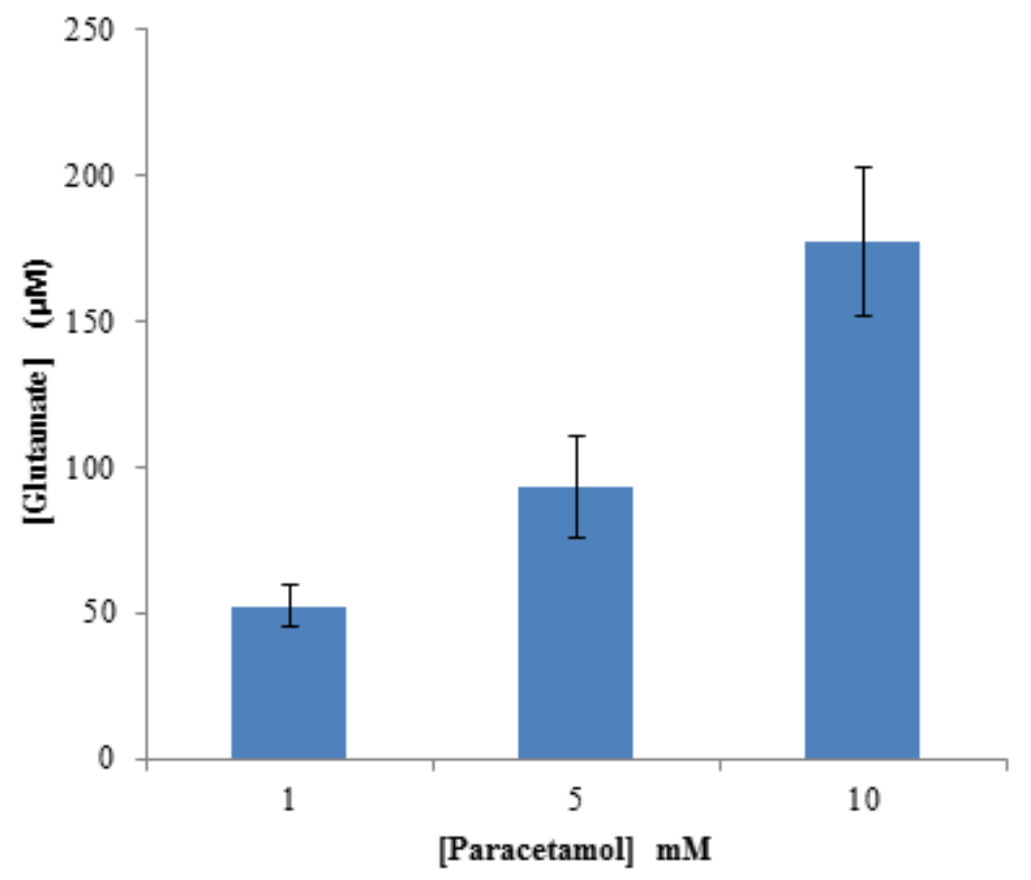

Figure 6 


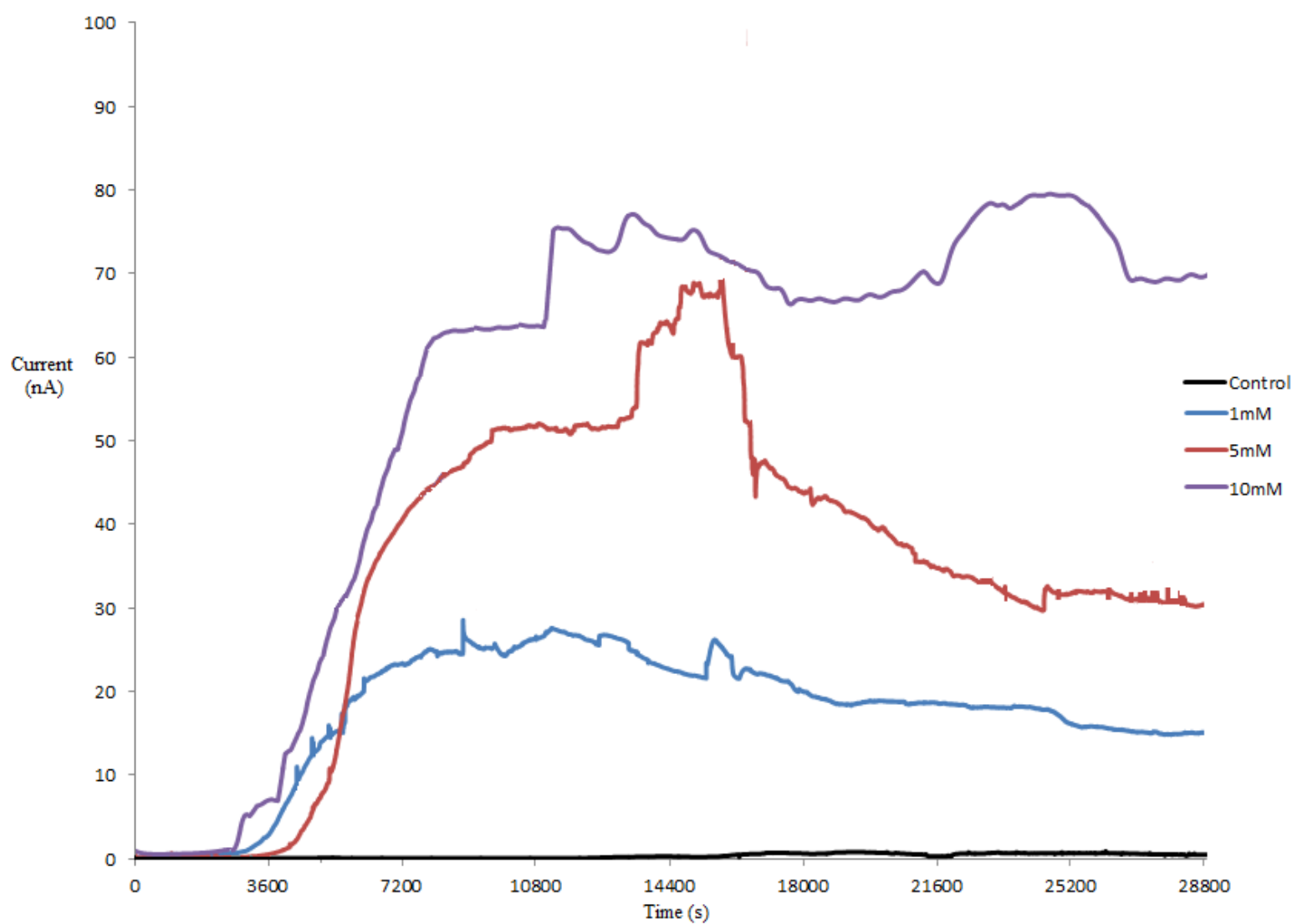

Figure 7 


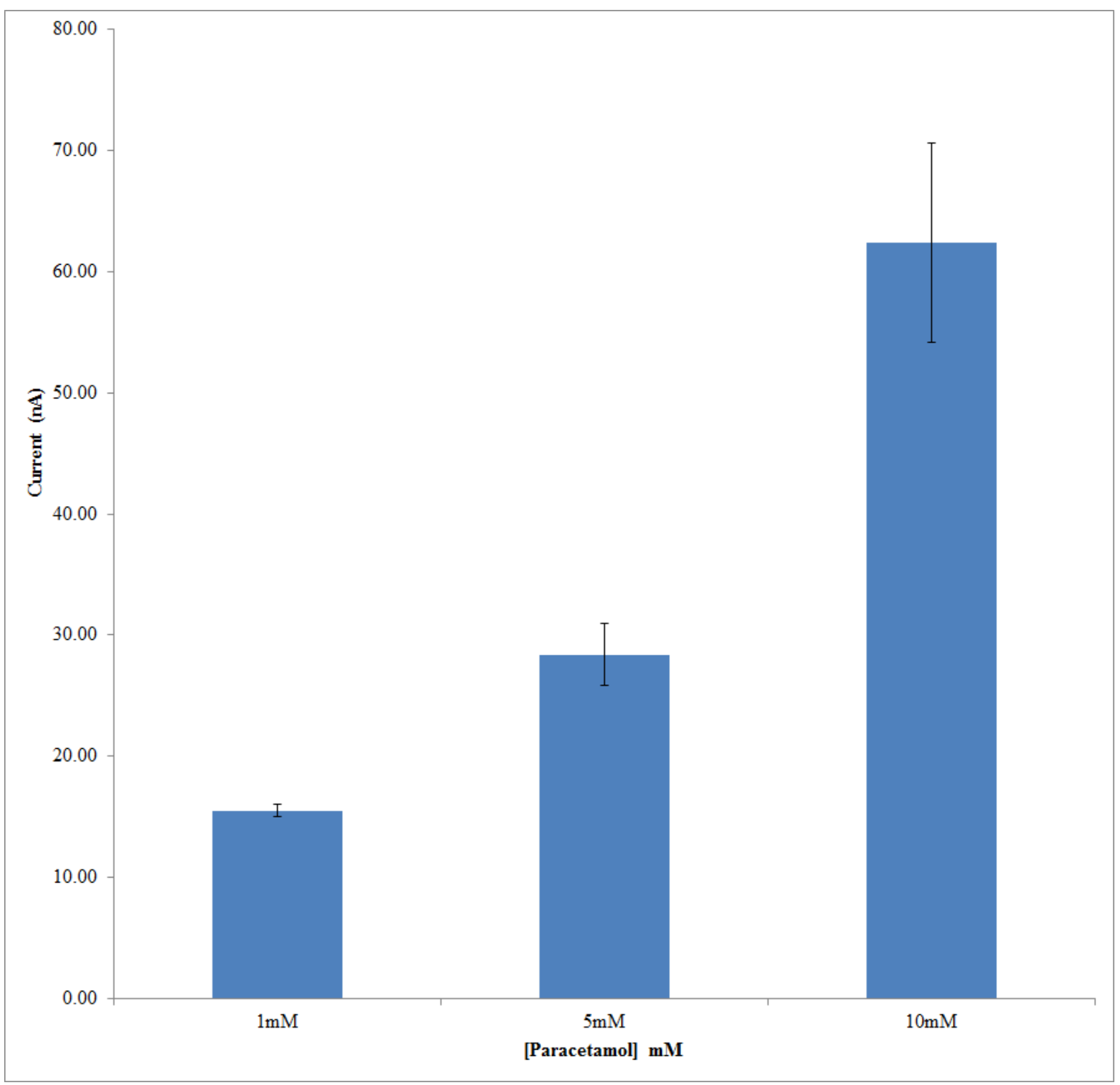

Figure 8 


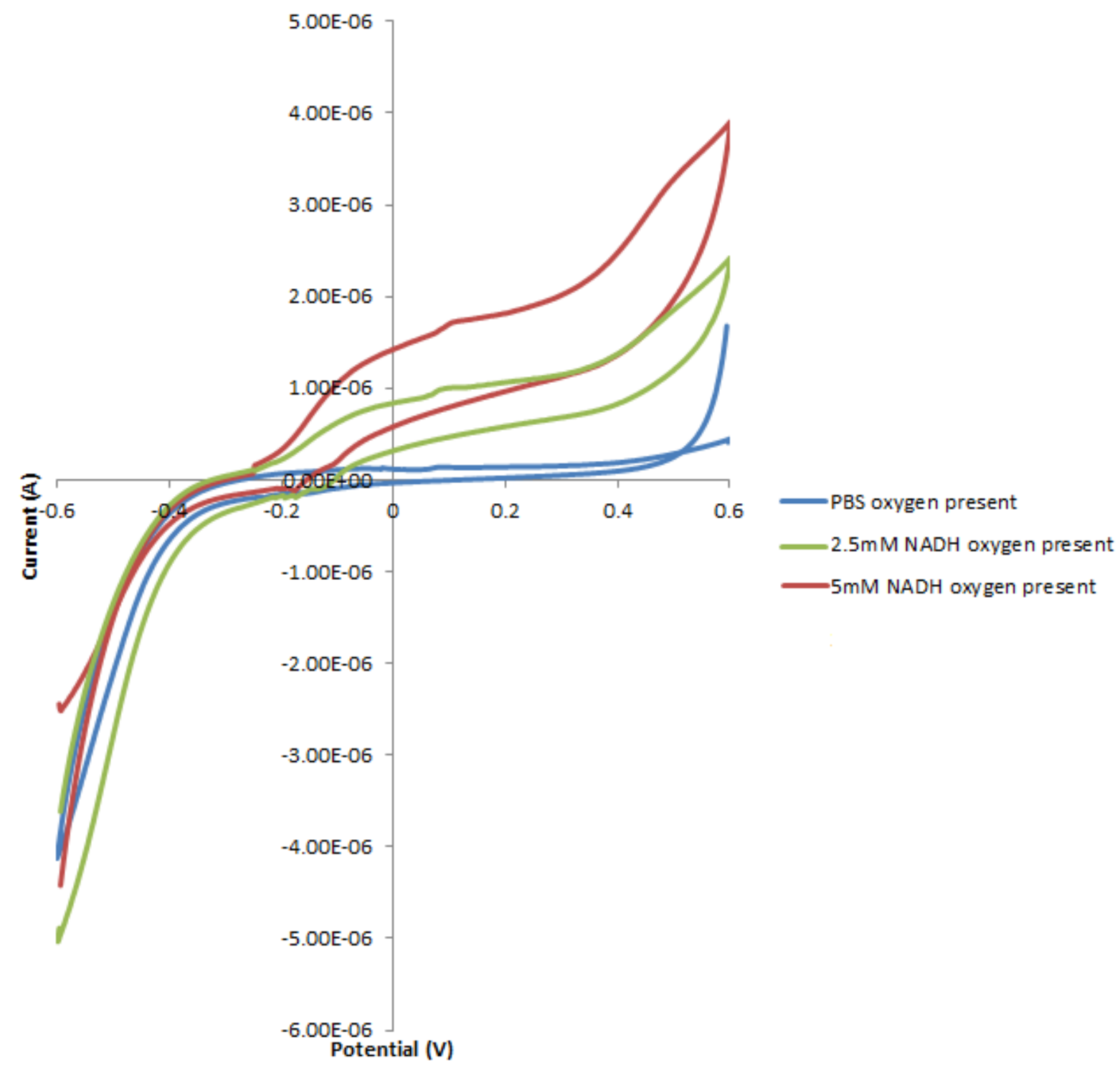

Supplementary Figure 1 


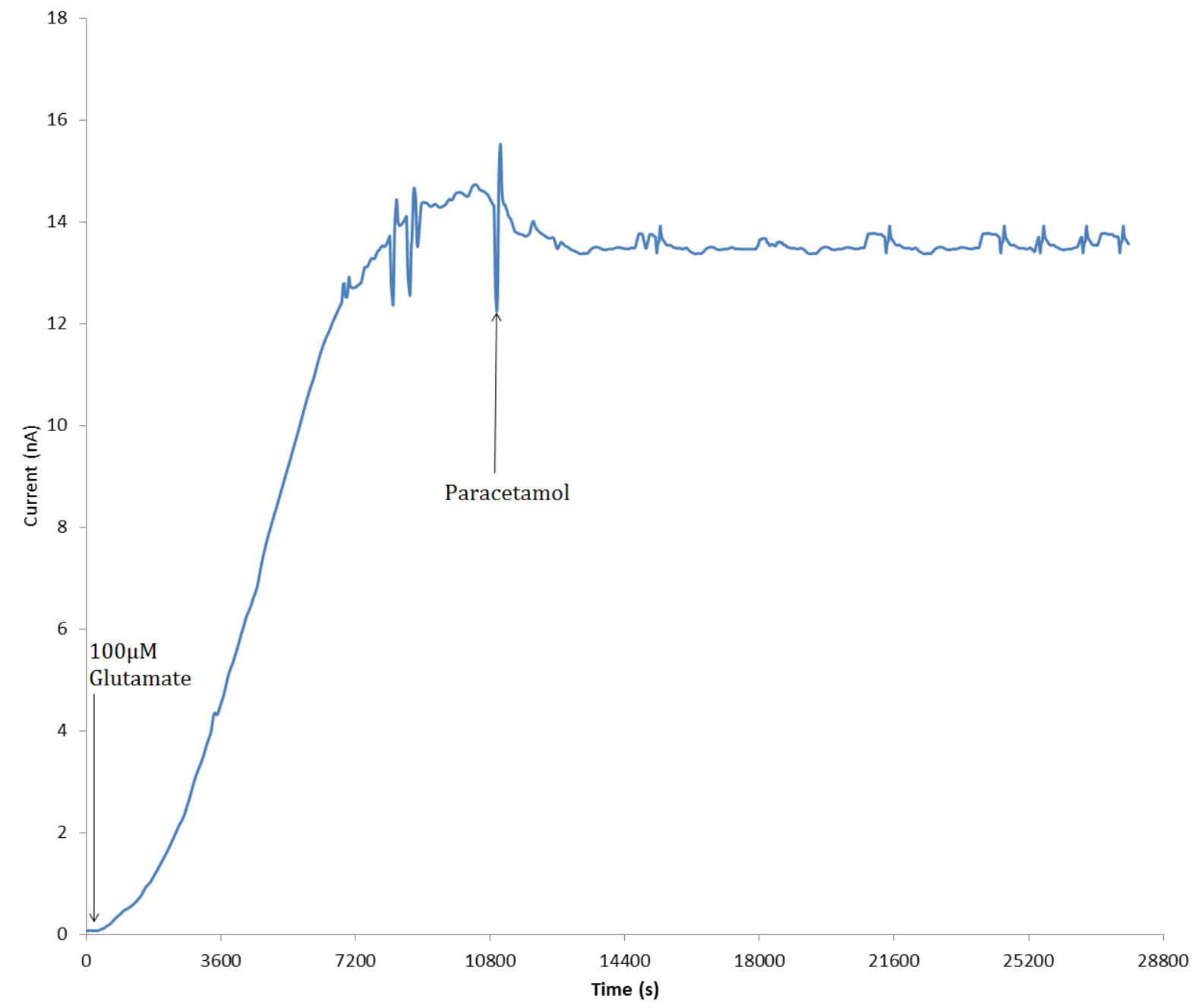

Supplementary Figure 2 


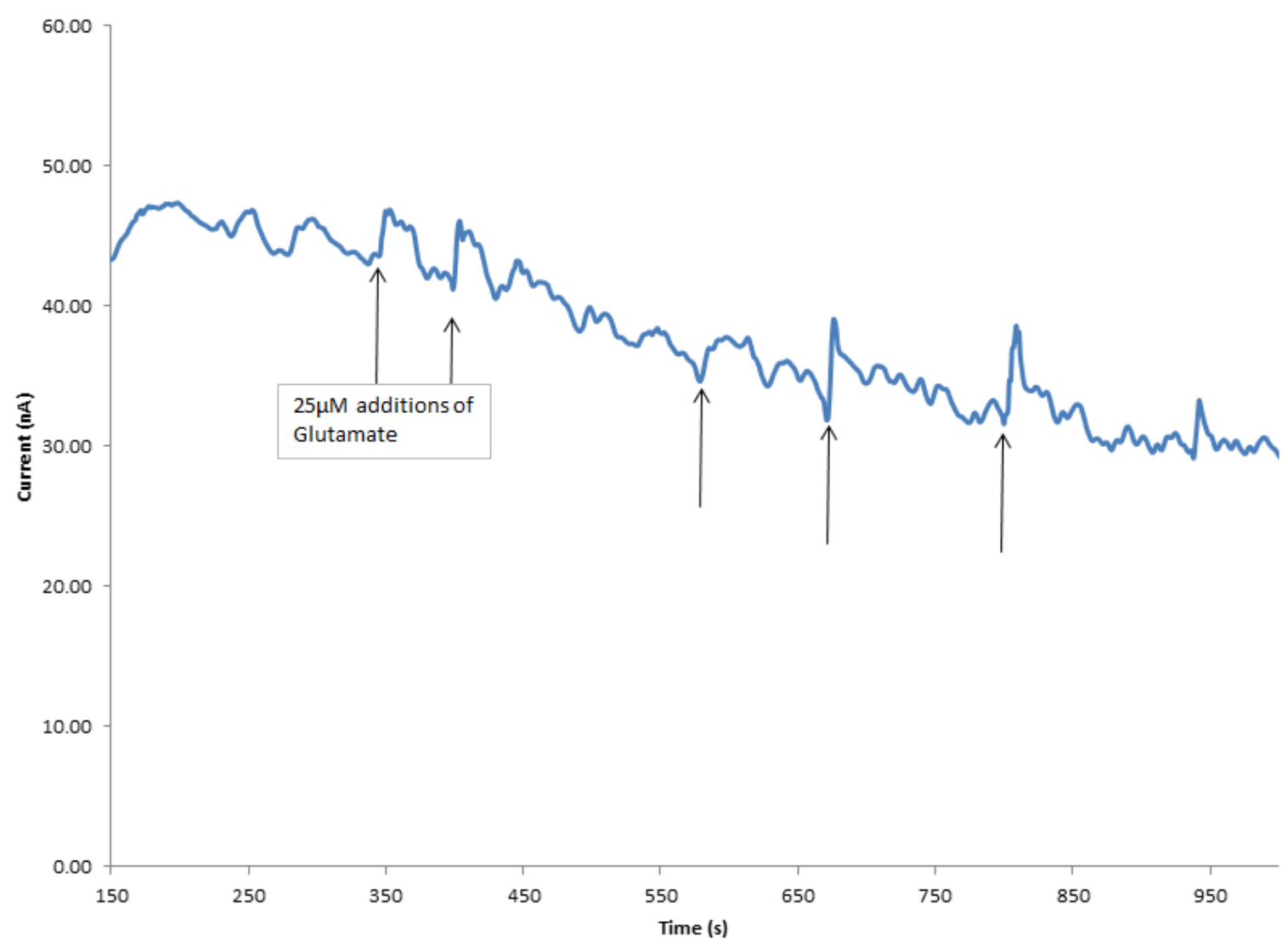

Supplementary Figure 3 